\title{
A Study on the Information Technology Acceptance of Fishery Industry in the 4th Industrial Revolution
}

\section{4차 산업혁명 시대에서 수산업의 정보기술 수용에 관한 \\ 연구}

Hakyun $\mathrm{Kim}^{1}$

김하균 ${ }^{1}$

${ }^{1}$ Professor, Division of Business, Pukyong National University, Korea, kimhk@pknu.ac.kr

\begin{abstract}
In the fishery industry, digital innovation called the 4th industrial revolution is continuously spreading. The fishery industry is also in the process of changing jobs related to digital technology. The change and importance of digital innovation in the fishery industry should be identified. In order to convert the existing model in the fishery industry, a full-scale study should be conducted. In the changing environment of the paradigm shift, the fishery industry must also come up with a strategy to secure a competitive advantage. Strategies and operations for the growth and survival of the fishery industry must change along with the 4th industrial revolution. In order to improve the survival and profitability of the fishery industry, it is fundamentally important to introduce information technology and recognize its value. Because the speed of change is fast, the fishery industry is highly likely to go out of business. In order to solve the chronic problems of the fishery industry, the role of the 4th industrial revolution is necessary. The purpose of this study is to analyze the relationship between the environmental factors of the introduction of information technology in the fishery industry and the impact on the value perception of fishery development and profitability improvement. For the basic statistical analysis of the questionnaire, SPSS 22.0, a statistical package, was used. For hypothesis testing, concentrated validity and discriminant validity were verified using the structural equation package Smart PLS 2.0. Factors that determine the environmental factors of the introduction of information technology are divided into external environment of fishery, internal environment of fishery, and environment of public sector. The recognition of the value of fishery development was divided into opportunity capture and process improvement. A summary of the study follows. First, the environmental factors of the introduction of information technology in the fishery industry and the recognition of the value of the development of the fishery industry were partially adopted. Public sector environment and opportunity seizing did not have a significant effect. Second, the value recognition of the development of the fishery industry had a significant effect on profitability improvement.
\end{abstract}

Keywords: External Environment, Internal Environment, Public Sector Environment, Opportunity Seizing, Process Improvement, Profitability Improvement

요약: 수산업에서도 4차 산업혁명이라는 디지털 혁신이 계속적으로 확산되고 있다. 수산업도 디지털 기술과 관련된 직업군은 변화의 과정에 있다. 수산업에서 디지털 혁신의 변화와 중요성을 파악하여야 한다. 수산업에서 기존모델을 전환하기 위한 본격적

Received: June 14, 2021; ${ }^{\text {st }}$ Review Result: July 30, 2021; $2^{\text {nd }}$ Review Result: September 14, 2021

Accepted: October 31, 2021 
연구가 진행되어야 한다. 변화하는 패러다임 전환의 환경 속에서 수산업도 경쟁우위를 확보하는 전략을 도출해야 한다. 수산업의 성장과 생존을 위한 전략 및 운영은 4차 산업혁명과 더불어 변화하여야 한다. 이러한 수산업의 생존과 수익성 향상을 위해서는 기본적으로 정보기술도입과 수산업 발전의 가치인식이 중요하다. 변화의 속도가 빠르기 때문에 수산업도 도태될 가능성이 높기 때문이다. 수산업의 고질적인 문제를 해결하기 위해서는 4차 산업혁명의 역할이 필요하다. 본 연구는 수산업 분야에서 정보기술도입의 환경적 요인이 수산업발전의 가치인식과 수익성향상에 미치는 영향관계를 분석하는데 연구의 목적이 있다. 설문지의 기본통계분석을 위해 통계 패키지인 SPSS 22.0 을 사용하였다. 가설검정을 위해 구조방정식 패키지 Smart PLS 2.0을 사용하여 집중타당성과 판별타당성을 검증하였다. 정보기술도입의 환경적 요인을 결정하는 요인으로 수산업의 외부환경, 수산업의 내부환경, 공공부문 환경으로 나누었다. 수산업 발전의 가치인식은 기회 포착과 프로세스 개선으로 나누었다. 연구의 요약은 다음과 같다. 첫째, 수산업에서 정보기술도입의 환경적요인과 수산업 발전의 가치인식은 부분채택되었다. 공공부문환경과 기회 포착은 유의한 영향을 미치지 못하였다. 둘째, 수산업 발전의 가치인식은 수익성 향상에 유의한 영향을 미쳤다.

핵심어: 외부환경, 내부환경, 공공부문환경, 기회 포착, 프로세스 개선, 수익성 향상

\section{1. 서론}

4차 산업혁명은 인공지능시스템의 현실화를 기본으로 새로운 시대를 열어가고 있다. 정보기술의 혁신을 통하여 새로운 부가가치의 창출과 함께 소득의 증가와 삶의 질도 향상을 기대하고 있다. 4차 산업혁명의 패러다임 전환과 함께 기업과 산업은 혁신역량을 강화하고 부가가치를 창출해야 한다. 이러한 4차 산업혁명은 전 분야에 걸쳐 이루어지고 있으며, 농업과 수산업에서도 영향을 주고 있다.

해양수산부는 수산업의 활성화를 위하여 ICT 융복합 기술개발을 위해 노력하고 있다. 지속적인 어촌의 고령화에 대한 수산업의 경쟁력을 높이는 방법은 4차 산업혁명 기술확산이 절대적이다. 이는 농촌 및 1 차산업에 종사하는 모든 산업이 동일하다. 우리나라는 디지털 산업 전환기를 통해 반도체, 정보기술 등은 4차 산업혁명의 기반 $(5 \mathrm{G})$ 과 원천기술, 원천산업을 선도할 수 있는 디지털 기술을 보유하고 있다. 이 원천기술을 중심으로 한 국가산업기술의 융성전략과 함께 수산업을 포함한 각종 고유전통산업과의 융합특성을 고도화하는 차원에서 치밀하게 접근할 필요가 있다.

혁신적으로 발전하고 있는 ICT기술은 4차 산업혁명을 성공시키기 위한 핵심이 될 것이다. 이러한 정보기술이 수산업의 환경과 어떠한 영향관계가 있는지를 실증적으로 연구할 것이다. 수산환경과 4차 산업혁명과 연결을 시도하는 기본 연구가 될 것이다. 4차 산업혁명 전에는 상호 단절되었던 학문, 산업의 분야경계를 넘어섰다. 이러한 패러다임의 환경적 변화 속에서 수산업의 발전 방향을 제시하고자 한다.

본 연구는 수산업에서 정보기술의 환경적 요인(수산업의 외부환경, 수산업의 내부환경, 공공부문환경)이 수산업의 가치인식(기회 포착, 프로세스 개선)과 수익성 향상에 미치는 영향을 조사하였다. 수산업에서 수익성 향상을 위한 매개변수로 수산업 발전의 가치인식으로 설정하였다. 수산업에서 4차 산업혁명 정보기술도입을 위한 환경적 요인을 
실증적으로 분석한 연구이다.

\section{2. 이론적 배경}

\section{1 정보기술과 제4차 산업혁명}

정보기술의 발전 추세를 통해 예측되는 4차 산업혁명은 종전의 정보사회에 비해 더욱 심화, 고도화될 것이다. 이러한 4차 산업혁명은 수산업에서도 예외가 없다. 수산환경의 변화를 주도할 것이다. 지능정보사회는 시간, 공간, 및 지식의 확장됨에 따라 새로운 가능성을 보여주고 있다.

해외에서 노르웨이, 아이슬란드 등의 수산강국은 4차 산업혁명의 핵심기술인 센싱(sensing), 네트워크, 인공지능, 보안 등으로 구성된 사물인터넷의 활용, 로봇기술을 활용한 전 공정의 자동화, 빅데이터 등 핵심 첨단기술을 도입해 수산업의 체계적인 관리와 스마트시스템을 구축하고 있다[1]. 특히 양식산업 첨단화의 첨병인 노르웨이의 스마트 양식시스템은 원격삼시, 제어, 생산량 관리 등으로 4차 산업혁명을 이끌고 있다. 세계적으로 수산업은 속도, 영향력, 범위 등에서 타 산업과 비교하면, 걸음마 단계에 있다. 특히, 정보기술이 발달한 우리나라의 경우 4차 산업혁명을 수산업에서의 응용은 너무 늦다고 할 수 있다[2].

\section{2 수산업에서 정보기술도입의 환경적 요인}

외부환경 요인으로 대부분의 기업은 4차산업 혁명에서 경쟁적 우위를 점하고 싶어한다. 경쟁적 우위를 갖고 있는 산업은 외부산업과 연계하여 경쟁적 우위를 지킨다. 이러한 외부 산업과의 연계는 인공지능, 빅데이터, 사물인터넷 등 4차 산업혁명 기술과 밀접한 관계가 있다. 외부 환경변화는 수산업의 정보기술 도입에 영향을 미칠 수 있는 조건이다[3].

내부환경 요인으로 수산업 내에서 지속적 경쟁력을 갖기 위해서 내부핵심역량이 중요하다. 수산업 내에서 경쟁을 심하게 경험할수록 4차 산업혁명 정보기술의 수용 압력을 강하게 받는다. 내부환경요인의 변화는 기업의 정보기술 도입의 패러다임에 영향을 주는 요인이다[4].

공공부문 환경 요인은 수산업에서 정부정책 변화에 따른 영향이다. 정부 및 공공기관의 정책 환경 변화는 정보기술 도입에 영향을 미친다[5]. 정부의 정책적 환경 변화는 4차산업의 정보기술 도입 및 확산의 패러다임에 영향을 미치는 요인이며, ICT환경변화의 패러다임수용에 영향을 준다.

\section{3 수산업 발전의 가치인식 및 수익성 향상}

기회 포착은 변화속에서 표출되는 현상을 파악하여 기업과 산업에서 기회를 발견하는 것이다. 기회포착 전략은 기회를 포착하기 위해 시장과 산업을 지속적으로 모니터링해야 한다[6]. 이러한 모니터링의 범위는 산업구조를 개선할 모든 것이 포함된다[7]. 기회 포착은 보유자원이 한정적이기 때문에 파악된 기회 중 적절한 시기를 선택해야 한다. 시장에 안정적으로 진입하여 생존하는 것을 우선하는 경우는 환경변화를 탐색하고 기회를 포착하여 구현시키는 것이 중요하다. 
프로세스 개선은 업무프로세스를 개선하여 기업의 성과를 개선하는 것이다[8]. 예측 분석을 하기 위해서는 데이터 수집, 변수 및 요인 생성, 예측 모델 설정, 모델의 유의성 검증의 프로세스를 거치게 된다. 따라서 프로세스 개선이 중요한 역할을 하게 된다. 특히 변수 및 요인 생성은 최적의 영향 변수를 선정하는 것이 중요하다[9]. 프로세스는 투입 이후 프로세스를 거쳐 새로운 산출물을 만들어 내는 순차적인 흐름을 의미한다. 프로세스는 투입과 전환의 과정을 거쳐 부가가치 산출로 이어지는 행위들로 구성되어 있다[10].

수산업의 정보기술 도입은 수익을 창출하기 위해서이다[11]. 수산업의 계속적 가치하락으로 수익을 낼 수 없다면 수산업 자체가 의미가 없다. 수산업에서 수익성 향상을 우선적으로 따질 수밖에 없으며 4차산업의 핵심기술인 빅데이터, 인공지능, 사물인터넷 등의 정보기술의 도입은 필수적이다. 따라서 높은 가치의 수산업을 개발하는 것이 최고의 목표가 되어야 한다. 수산업에서 수익성 향상을 위해서는 기술적으로 4차 산업혁명의 정보기술이 도입되어야 한다.

\section{3. 연구설계}

\section{1 연구모형}

4차산업 혁명이 시작되면서 모든 분야에 영향을 주고 있다. 따라서 4차 산업혁명의 정보기술을 도입하기 위한 환경적요인이 중요하다. 환경적 요인이 중요한 이유는 4차 산업혁명이 변화의 중심에 있기 때문이다. 수산업에서도 정보기술을 도입하기 위해서는 환경적 요인이 중요하다. 가설검정을 위해 설문조사 방법이 사용되었다. 설문조사기간은 2020년 4월부터 30일간 수산업의 종사자를 대상으로 지속되었다. 연구모형은 수산업에서 정보기술도입의 환경적요인이 수산업의 가치인식과 프로세스 개선의 관계를 분석하는 데 중점이 있다. 정보기술도입의 환경적 요인으로는 수산업의 외부환경, 수산업의 내부환경, 공공부문 환경으로 나누었다[12]. 수산업 발전의 가치인식은 기회 포착, 프로세스 개선으로 나누었다. 연구모형을 제시하면 [그림 1]과 같다.

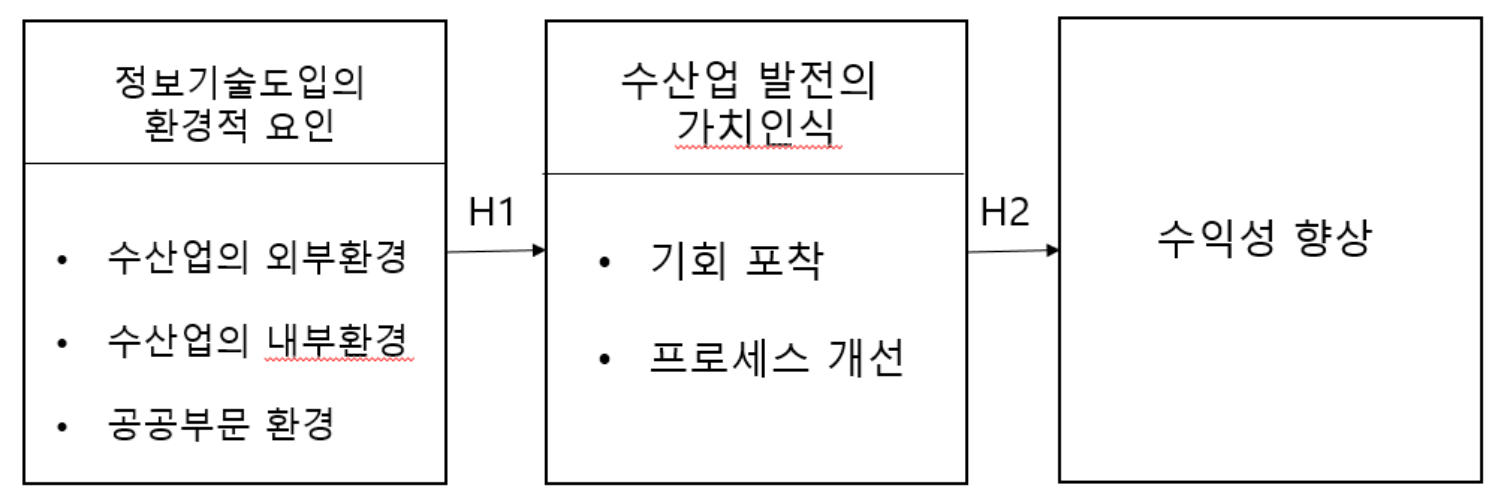

[그림 1] 연구모형

[Fig. 1] Research Model

\section{2 연구가설}

수산업에서 정보기술도입의 요인은 4차 산업혁명 시대의 정보기술을 통하여 다양한 
방식으로 발전되었다. 4차 산업혁명의 분야에 따라 여러가지의 정보기술 유형이 분류될 수 있다. 연구자마다 정보기술도입의 형태를 분류하여 제시하는데, 일반적으로 국내외 연구에서 환경적 요인은 외부환경, 내부환경 및 공공부문 환경으로 구분한다[4]. 수산업 발전의 가치를 높이기 위한 인식방법으로는 기회 포착과 프로세스 개선으로 구분하였다[13]. 수산업 발전의 가치인식은 수익성 향상에 영향을 준다. 선행연구를 기반으로 다음과 같은 가설을 설정하였다.

가설 H1-1-1 수산업의 외부환경은 기회 포착에 유의적인 영향을 미칠 것이다. 가설 H1-2-1 수산업의 내부환경은 기회 포착에 유의적인 영향을 미칠 것이다.

가설 H1-3-1 공공부문환경은 기회 포착에 유의적인 영향을 미칠 것이다.

가설 H1-1-2 수산업의 외부환경은 프로세스 개선에 유의적인 영향을 미칠 것이다. 가설 H1-2-2 수산업의 내부환경은 프로세스 개선에 유의적인 영향을 미칠 것이다. 가설 H1-3-2 공공부문환경은 프로세스 개선에 유의적인 영향을 미칠 것이다.

가설 $\mathrm{H} 2-1$ 기회 포착은 수익성 향상에 유의적인 영향을 미칠 것이다.

가설 H2-1 프로세스 향상은 수익성 향상에 유의적인 영향을 미칠 것이다.

\section{3 설문조사 및 통계처리방법}

본 연구에서 측정항목은 기존연구에서 사용하였던 설문 문항을 본 연구의 취지에 맞게 재구성하여 사용하여 각 문항을 Likert 5점 척도(scale)로 측정하였다. 설문지의 기본통계분석을 위해 통계 패키지인 SPSS 22.0 을 사용하였다. 가설검정을 위해 구조방정식 패키지 Smart PLS 2.0을 사용하여 집중타당성과 판별타당성을 검증하였다. 요인로딩 값, Cronbach' a 및 구성신뢰도 (Composite Reliability) 및 각 요인의 평균분산추출 값 (Average Variance Extraction)을 검증했다. 0.6 이상의 요인적재 값, Cronbach' $\alpha$ 값은 0.7 이상, 구성신뢰도 값은 0.7 이상, 및 0.5 이상의 분산추출지수 값이 일반적으로 유효한 것으로 간주된다.

\section{4. 실증분석 및 결과}

\section{1 자료수집 및 표본의 특성}

설문조사를 위하여 수산업 종사자에게 4차 산업혁명의 중요성을 설문지에서 1쪽으로 설명한 다음에 설문조사를 실시하였다. 총 350 명의 사용자가 설문조사에 응하였으며, 이중에서 불성실하게 답변한 29명을 제외한 321 명의 설문지가 사용되었다. 설문조사는 2020년 4월부터 한달동안 진행되었다. 기본통계조사를 살펴보면 다음과 같다. 응답자의 성별은 남자 $83 \%$ (266명), 여자 $17 \%$ (55명)이다. 남자가 월등히 많은 것으로 분석되었다. 학력은 초등학교 졸 $13 \%$ (42명), 중학교 졸 $24 \%(77$ 명), 고등학교 졸 $37 \%(119$ 명), 대졸이상 $26 \%(83$ 명)로 고졸과 대졸이 많은 것으로 나타났다. 수산업의 경력은 10 년이상 $53 \%$ (170명), 11-20년 29\%(61명), 21년이상 18\%(90명)이다. 연령으로 보면 30세이하 11\%(35명), 31-40세 31\%(100명), 41-50세 32\%(103명), 51세이상 26\%(83명)이다. 수산업의 종사분야를 보면 수산어획 $53 \%$ (170명), 수산양식 $16 \%$ (51명), 수산가공 $21 \%$ (100명)인 
것으로 나타났다.

\section{2 자료의 분석방법}

설문지의 정확성을 위해 신뢰성과 타당성분석이 [표 1]과 [표 2]에 표시되어 있다. 신뢰성은 Cronbach's $\alpha$ 가 0.7 이상으로 문제가 없다. 집중타당성은 요인 적재값 0.6 , 구성신뢰도 $0.7, \mathrm{AVE}$ 값이 0.5 이상으로 문제가 없다. 판별타당성은 $\mathrm{AVE}$ 의 제곱근값이 상관계수의 종과 횡의 값보다 크므로 문제가 없다.

[표 1] 신뢰도 및 집중 타당성 분석결과

[Table 1] Reliability and Internal Consistency Results

\begin{tabular}{|c|c|c|c|c|}
\hline 변수 & 요인적재 값 & AVE & C. R. & Cronbach's $\alpha$ \\
\hline \multirow{4}{*}{$\begin{array}{l}\text { 수산업의 } \\
\text { 외부환경 }\end{array}$} & 0.830 & \multirow{4}{*}{0.570} & \multirow{4}{*}{0.840} & \multirow{4}{*}{0.757} \\
\hline & 0.760 & & & \\
\hline & 0.725 & & & \\
\hline & 0.691 & & & \\
\hline \multirow{4}{*}{$\begin{array}{l}\text { 수산업의 } \\
\text { 내부환경 }\end{array}$} & 0.669 & \multirow{4}{*}{0.512} & \multirow{4}{*}{0.807} & \multirow{4}{*}{0.781} \\
\hline & 0.748 & & & \\
\hline & 0.751 & & & \\
\hline & 0.689 & & & \\
\hline \multirow{4}{*}{ 공공부분환경 } & 0.812 & \multirow{4}{*}{0.650} & \multirow{4}{*}{0.881} & \multirow{4}{*}{0.820} \\
\hline & 0.838 & & & \\
\hline & 0.836 & & & \\
\hline & 0.773 & & & \\
\hline \multirow{4}{*}{ 기회포착 } & 0.898 & \multirow{4}{*}{0.579} & \multirow{4}{*}{0.941} & \multirow{4}{*}{0.954} \\
\hline & 0.836 & & & \\
\hline & 0.967 & & & \\
\hline & 0.938 & & & \\
\hline \multirow{3}{*}{ 프로세스 개선 } & 0.883 & \multirow{3}{*}{0.541} & \multirow{3}{*}{0.841} & \multirow{3}{*}{0.905} \\
\hline & 0.937 & & & \\
\hline & 0.939 & & & \\
\hline \multirow{4}{*}{ 수익성 향상 } & 0.938 & \multirow{4}{*}{0.720} & \multirow{4}{*}{0.920} & \multirow{4}{*}{0.971} \\
\hline & 0.972 & & & \\
\hline & 0.963 & & & \\
\hline & 0.963 & & & \\
\hline
\end{tabular}

[표 2] 상관관계 및 판별타당성 분석결과

[Table 2] Correlation and Discriminant Validity

\begin{tabular}{|c|c|c|c|c|c|c|c|}
\hline 변수 & $\mathrm{AVE}$ & 1 & 2 & 3 & 4 & 5 & 6 \\
\hline 수산업의 외부환경 & 0.570 & 0.754 & & & & & \\
\hline 수산업의 내부환경 & 0.512 & 0.474 & 0.715 & & & & \\
\hline 공공부문환경 & 0.650 & 0.563 & 0.543 & 0.806 & & & \\
\hline 기회포착 & 0.579 & 0.570 & 0560 & 0.468 & 0.760 & & \\
\hline
\end{tabular}




\begin{tabular}{|c|c|c|c|c|c|c|c|}
\hline 프로세스 개선 & 0.541 & 0.650 & 0.563 & 0.631 & 0.669 & 0.735 & \\
\hline 수익성 향상 & 0.720 & 0.554 & 0.554 & 0.448 & 0.627 & 0.504 & 0.848 \\
\hline
\end{tabular}

\section{3 연구모형의 검증}

구조모형은 Smart PLS 2.0을 사용하였으며 구조모형을 통해서는 연구모형의 변수들 간의 경로계수와 결정계수(R2)결과 값을 도출하였다. R2값이 0.26 이상이면 적합도가 높은 편이며, 0.26 0.13이면 중간이다. 0.13이하는 적합도가 낮은 것으로 표시할 수 있다[14]. 기회포착(0.436), 프로세스 개선(0.558) 및 수익성 향상(0.680)에 대한 결정계수(R2)값은 상으로 나타났다.

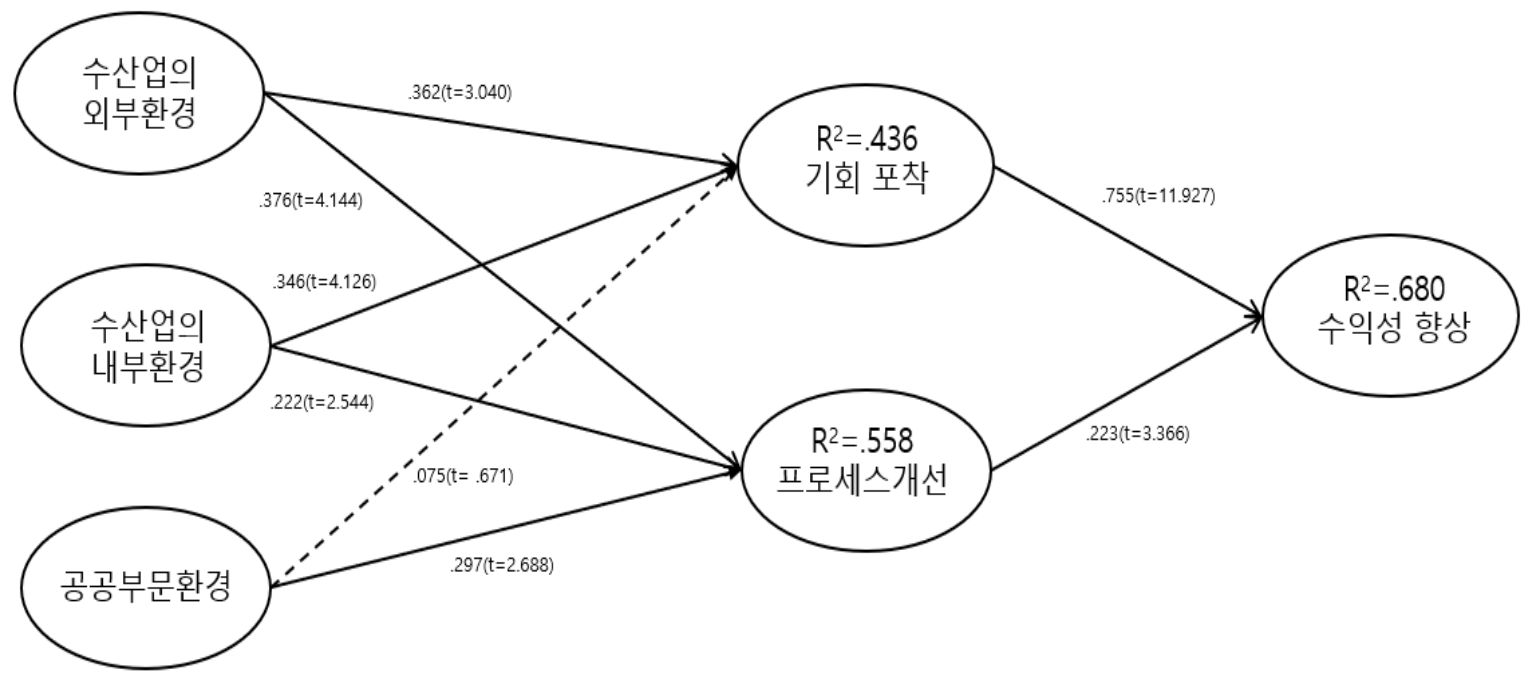

[그림 2] 구조모형 분석결과

[Fig. 2] The Results of Research Model

가설 $\mathrm{H} 1$ 은 부분채택 되었다. 가설 $\mathrm{H} 2$ 는 채택되었다. 가설 H1-1-1의 “수산업의 외부환경은 기회 포착에 영향을 미칠 것이다"라는 가설은 채택되었다. 수산업의 외부환경은 기회 포착 $(\beta=0.362, \mathrm{t}=3.040, \mathrm{p}<0.05)$ 에 유의한 영향을 미치는 것으로 나타났다. 이는 수산업에서 정보기술의 도입의 외부환경이 기회 포착에 영향을 준다는 것이다. 가설 H1-1-2의 “수산업의 내부환경은 기회 포착에 영향을 미칠 것이다"라는 가설은 채택되었다. 수산업의 내부환경은 기회 포착 $(\beta=0.346, \mathrm{t}=4.126, \mathrm{p}<0.05)$ 에 유의한 영향을 미치는 것으로 나타났다. 이는 수산업에서 정보기술의 도입의 내부환경이 기회 포착에 영향을 준다는 것이다. 가설 H1-1-3의 “공공부문환경 외부환경은 기회 포착에 영향을 미칠 것이다"라는 가설은 기각되었다. 공공부문환경은 기회 포착 $(\beta=0.075, \mathrm{t}=0.671$, $\mathrm{p}<0.05)$ 에 유의한 영향을 미치지 못하였다. 이는 수산업에서 공공부문은 기회 포착에 영향이 없다는 것이다. 공공부문의 환경개선은 느리게 진행되어 수산업 종사자의 경우 기회 포착을 하기 힘들다는 것이다.

가설 H1-1-2의 “수산업의 외부환경은 프로세스 개선에 영향을 미칠 것이다"라는 가설은 채택되었다. 수산업의 외부환경은 프로세스 개선 $(\beta=0.376, \mathrm{t}=4.144, \mathrm{p}<0.05)$ 에 유의한 
영향을 미치는 것으로 나타났다. 이는 수산업에서 정보기술의 도입의 외부환경이 프로세스 개선에 영향을 준다는 것이다. 가설 H1-2-2의 “수산업의 내부환경은 프로세스 개선에 영향을 미칠 것이다"라는 가설은 채택되었다. 수산업의 내부환경은 프로세스 개선 $(\beta=0.222, \mathrm{t}=2.544, \mathrm{p}<0.05)$ 에 유의한 영향을 미치는 것으로 나타났다. 이는 수산업에서 정보기술의 도입의 내부환경이 프로세스 개선에 영향을 준다는 것이다. 가설 H1-3-2의 “공공부문환경 외부환경은 기회 포착에 영향을 미칠 것이다”라는 가설은 채택되었다. 공공부문환경은 프로세스 개선기회 포착 $(\beta=0.297, \mathrm{t}=2.688, \mathrm{p}<0.05)$ 에 유의한 영향을 미쳤다. 이는 기존의 연구[7]와 같다.

가설 H2-1의 "기회 포착은 수익성 향상에 영향을 미칠 것이다"라는 가설은 채택되었다. 기회 포착과 수익성 향상 $(\beta=0.755, \mathrm{t}=11.927, \mathrm{p}<0.05)$ 는 유의한 영향을 미치는 것으로 나타났다. 가설 $\mathrm{H} 2-2$ 의 “프로세스 개선은 수익성 향상에 영향을 미칠 것이다"라는 가설은 채택되었다. 프로세스 개선은 수익성 향상 $(\beta=0.233, \mathrm{t}=3.366, \mathrm{p}<0.05)$ 에 유의한 영향을 미치는 것으로 나타났다.

[표 3] 가설검정 결과요약

[Table 3] Results of Hypothesis Tests for the Research Model

\begin{tabular}{|c|c|c|c|}
\hline 가설 경로 & 표준화 계수( $\beta$ ) & $\mathrm{t}$-value & 채택 유무 \\
\hline H1-1-1: 수산업의 외부환경 $\rightarrow$ 기회 포착 & 0.362 & 3.040 & 채택 \\
\hline H1-1-2: 수산업의 내부환경 $\rightarrow$ 기회 포착 & 0.346 & 4.126 & 채택 \\
\hline H1-1-3: 공공부문 환경 $\rightarrow$ 기회 포착 & 0.075 & 0.671 & 기각 \\
\hline $\begin{array}{l}\text { H1-1-2: 수산업의 외부환경 } \rightarrow \text { 프로세스 } \\
\text { 개선 }\end{array}$ & 0.376 & 4.144 & 채택 \\
\hline $\begin{array}{l}\text { H1-2-2: 수산업의 내부환경 } \rightarrow \text { 프로세스 } \\
\text { 개선 }\end{array}$ & 0.222 & 2.544 & 채택 \\
\hline H1-3-2: 공공부문 환경 $\rightarrow$ 프로세스 개선 & 0.297 & 2.688 & 채택 \\
\hline H2-1: 기회 포착 $\rightarrow$ 수익성 향상 & 0.755 & 11.927 & 채택 \\
\hline H2-2: 프로세스 개선 $\rightarrow$ 수익성 향상 & 0.223 & 3.366 & 채택 \\
\hline
\end{tabular}

\section{5. 결론}

본 연구는 수산업에서 정보기술도입의 환경적 요인(수산업의 외부환경, 수산업의 내부환경, 공공부문환경이 수산업의 가치인식(기회 포착, 프로세스 개선)을 매개로 수익성 향상에 어떤 영향을 주는지 알아보기 위한 실증연구이다. 이를 위하여 정보기술도입의 환경적 요인, 수산업의 가치인식, 수익성 향상에 대한 기존문헌을 정리하였다. 또한, 기존연구를 바탕으로 연구모형과 연구가설을 설정하였으며, 리를 실증적으로 검증하였다. 본 연구의 실증분석결과를 요약하면 아래와 같다. 첫째, 정보기술도입의 환경적 요인이 수산업의 가치인식에 영향을 미친다는 가설 $\mathrm{H} 1$ 은 부분 채택되었다. 공공부문환경이 기회 포착에 유의한 영향을 미치지 못하였다. 수산업의 외부환경, 내부환경은 기회 포착에 유의한 영향을 미쳤다. 수산업의 외부환경, 내부환경, 공공부문환경은 프로세스 개선에 유의한 영향을 미쳤다. 둘째, 기회 포착과 프로세스 개선은 수익성 향상에 유의한 영향을 미쳤다는 가설 $\mathrm{H} 2$ 는 채택되었다.

본 연구를 통하여 수산업에서 정보기술도입의 환경적 요인이 수산업의 가치인식과 
수익성 향상에서 규명된 것은 다음과 같다. 현재 우리나라의 수산업의 상태는 노후화되어 있다. 수산업 기반의 재정비는 오랫동안 연구되었지만, 기본 수산업의 인프라가 미흡했다고 볼 수 있다. 제 4차 산업혁명의 시대에서 수산업의 패러다임 변화를 주도하여야 한다. 발전하고 있는 정보기술을 수산업에 반영하지 못한다면, 수산업의 사양화는 불가피하다. 로봇기술, 빅데이터 등의 수산선진국의 패러다임을 이해하고 따라가야 한다. 우리나라도 정보기술을 이용한 수산업 스마트화의 첫 단추가 시작되어야 한다. 우리나라 일부 지역의 수산업에서 4 차 산업혁명의 초기 단계로 사업이 추진되고는 있지만, 수산업의 패러다임을 바꿀 정도는 되지 않는다. 현재 정보기술로 인해 수산업의 가치사슬 전반을 바꾸어야 한다. 즉, 수산업의 산업 생태계가 바뀌어야 한다. 수산업은 제 4 차 산업혁명 시대에서 새로운 기술혁신을 받아들여야 할 시점에 있다.

수산업은 낮은 생산성과 정보기술과의 연계성 부족, 첨단기술과 융합을 하지 못해 산업 성장이 지연되고 있다. 오랫동안 지속하여온 보수성, 산업에서 복잡하게 얽힌 가치사슬은 수산업에서 먼저 해결해야 할 과제이다. 정보기술과 4 차 산업혁명은 이러한 문제를 해결할 첫 단추가 될 수 있다. 기존의 수산업에 머물러 있다면, 수산업은 스스로가 내리막길을 가는 결과만 초래하게 된다.

본 연구를 통하여 정보기술과 4차 산업혁명을 수산업에 비추어 재조명한다. 정보기술을 활용한 수산업에 관한 기초적인 연구를 수행할 것이다. 4차 산업혁명의 혁신기술을 응용하기 위한 수산업에 대한 환경적 요인을 실증적으로 분석하는 데 연구의 기여가 있다. 본 연구를 기반으로 수산업의 정보기술도입의 환경적 요인, 수산업의 가치인식, 수익성 향상에 대한 새로운 모델을 제안하고, 실증적으로 분석함으로써 4차산업에서 정보기술도입을 대상으로 연구한 결과를 확인할 수 있게 되었다.

\section{6. 감사의 글}

본 연구는 2020년도 (재)약수학술진흥회 교수학술연구비 지원사업(C-D-2020-1655)에 의해 수행되었으며, 연구비 지원에 감사드립니다.

\section{References}

[1] Y. Lee, Fisheries in the Era of the 4th Industrial Revolution: Industry, Academia, Research, Government, and Industry, Academia, Research, and Government Must Participate in the Future Industrialization of Fishery to Secure Competitiveness through New Value Creation, Busan Development Institute, (2016), Vol.161, pp.26-33.

[2] C. Ryu, The 4th Industrial Revolution and Fisheries Science and Technology-The Future of Industry, Proceeding of Conference of Korean Society for Fisheries Science and Aquaculture, (2017), May 11-12; Tongyeong, Korea.

[3] D. Acemoglu, R. Pascual, Robots and Jobs: Evidence from US Labor Markets, Journal of Political Economy, (2020), Vol.128, No.6, pp.218-224. DOI: http://dx.doi.org/10.1086/705716

[4] K. Zhu, K. Kraemer, S. Xu, Electronic business adoption by European firms: a cross-country assessment of the facilitators and inhibitors, European Journal of Information Systems, (2003), Vol.12, pp.251-268.

[5] L. Bornmann, J. Bauer, Which of the World's Institutions Employ the Most Highly Cited Researchers? An Analysis of the Data from highlycited.com, Journal of the Association for Information Science and Technology, (2015) Vol.66, No.10, pp.2146-2148. DOI: 10.1002/asi.23396

[6] J. Kim, C. Lee, Y. Cho, Technological Diversification, Core-technology Competence, and Firm Growth, Research Policy, (2016), Vol.45, No.1, pp.113-124. DOI: 10.1016/j.respol.2015.07.005 
[7] D. J. Teece, Explicating Dynamic Capabilities: The Nature and Micro Foundations of Sustainable Enterprise Performance, Strategic Management Journal, (2007), Vol.28, No.13, pp.1319-1350. DOI: 10.1002/smj.640

[8] J. Kim, H. Ka, A Study on the Analysis of IT Usage and Improvement Strategy for IT Utilization in Service Industry, Informatization Policy, (2011), Vol.18, No.14, pp.22-41.

[9] H. Cha, M. Yoo, A Study on Improve of the Demand Forecasting Process by Automated Feature Engineering, Proceedings of Symposium of the Korean Institute of communications and Information Sciences, (2019), January 2325; Pyeongchang, Korea.

[10] D. Docampo, L. Cram, Highly Cited Researchers: A Moving Target, Scient metrics, (2019), Vol.118, No.3, pp.10111025. DOI : $10.1007 / \mathrm{s} 11192-018-2993-2$

[11] S. K. Jeong, J. Y. Choi, J.Y. Kim, On the drivers of international collaboration: The impact of informal communication, motivation, and research resources, Science and Public Policy, (2013), Vol.41, No.4, pp.520-531.

[12] J. Kyung, D. Kwon, A Study on the Influencing Factors of the Acceptance of Information Technology in the Real Estate Industry in the Era of the Fourth Industrial Revolution, Journal of the Korean Real Estate Association, (2018), Vol.36, No.3, pp.183-198.

[13] J. Li, Y. F. Wang, Z. M. Zhang, C. H. Chu, Investigating acceptance of RFID in Chinese firms: The technologyorganization-environment framework, 2010 IEEE International Conference on RFID-Technology and Applications, (2010), June 17-19; Guangzhou, China, DOI: 10.1109/RFID-TA.2010.5529927

[14] J. Cohen, Statistical Power Analysis for the Behavioral Science(2nd), Routledge, (1988), pp.90-100, DOI: http://dx.doi.org/10.4324/9780203771587 